\title{
MODEL PENDIDIKAN MULTIKULTURAL RAMAH DI SEKOLAH ETHNO-RELIGIO SEGREGATION (E-RS) KOTA PONTIANAK
}

\author{
Iwan Supardi, Sumarno \\ FKIP Untan Pontianak, Universitas Negeri Yogyakarta \\ iwan.supardi26@gmail.com, sumarno_unj@yahoo.co.uk
}

\begin{abstract}
Abstrak
Penelitian ini bertujuan untuk memetakan pola dan mengukur intensitas hubungan antarkelompok siswa etnis Melayu, Dayak, Tionghoa, dan Madura di empat sekolah swasta berbasis etno-religi (ethno-religio segregation/E-RS) di Kota Pontianak: SMA Sultan Syarif Abdurrahman (Melayu-Islam), SMA Yayasan Pendidikan Kristen (YPK)[Dayak-Nasrani], SMA Kristen Immanuel (Tionghoa-Nasrani, Konghucu, Budha), dan Madrasah Aliyah Swasta (MAS) AlAnwar (Madura-Islam), berdasarkan sikap dan perilaku berprasangka (prejudice) dan stereotip terhadap etnis dan agama. Metode campuran kualitatif-kuantitatif digunakan pada tahap penelitian. Pada tahap pengembangan rumusan model pendidikan multikultural diuji melalui diskusi kelompok terbatas (Focus Group Discussion/FGD). Hasil penelitian menunjukkan bahwa sekolah E-RS menampilkan pola-pola hubungan antarkelompok etnis-agama yang khas, seperti ethno-sentrisme, cinta-benci (approach-avoidance) dan benci-cinta (avoidance-approach), saling membenci (avoidance-avoidance) atau berseteru (conflicting pair), dan saling menyukai/ mendukung (approach-approach) atau sebagai pasangan bulan madu (boneymoon). Kelompok etnis Madura cenderung dijadikan sebagai kelompok target konflik, sementara Tionghoa sebagai kelompok etnis sanjungan. Model pendidikan multikultural ramah dianggap sesuai diterapkan dalam program pendidikan di sekolah E-RS untuk membangun citra positif pada masingmasing kelompok agar prasangka (prejudice) dan bias anggapan (stereotip) dapat dikendorkan.
\end{abstract}

Kata kunci: prasangka (prejudice) dan stereotip, ethno-religio segregation (E-RS), model pendidikan multikultural ramah

\section{MULTICULTURAL EDUCATION RAMAH MODEL FOR ETHNO-RELIGIO SEGREGATED SCHOOLS (E-RS) KOTA PONTIANAK}

\author{
Iwan Supardi, Sumarno \\ FKIP Untan Pontianak, Universitas Negeri Yogyakarta \\ iwan.supardi26@gmail.com, sumarno_unj@yahoo.co.uk
}

\begin{abstract}
This research is intended to formulate patterns and measure the strength of the interethnicalreligious relation among students from four different ethnic groups of Malay, Dayak, Chinese, and Madurese at the ethno-religio segregated schools (E-RS) in Pontianak: Sultan Syarif Abdurrahman Senior High School (Malay-Islam), Christian Education Foundation Senior High School/ YPK (Dayak-Christian], Immanuel Christian Senior High School (ChineseChristian, Konghucu/Confucius, Buddha), dan Private Islamic Senior High School/MAS AlAnwar (Madurese-Islam), based on their prejudice-and stereotype attitudes toward ethnic and religion. The research applied qulititative-quantitative mixed method, and for developing the model, focus group discussion (FGD) was used. The findings show that E-RS have unique and critical interethnic-religious relation patterns, i.e. ethno-centrism, approach-avoidance, avoidance-approach, avoidance-avoidance (conflicting pair), and approach-approach (honeymoon). Madurese is treated as potential conflicting targeted group; Chinese as popular referring group among case groups. A model of Ramah (friendly attitudes and behaviours) in multicultural education is promoted to develop positive images among the groups to reduce potential prejudice and stereotypes.
\end{abstract}

Keywords: prejudice and stereotype, ethno-religio segregated schools (E-RS), multicultural education ramah model 


\section{Pendahuluan}

Pendekatan diskriminatif pemerintah kolonial Belanda, struktur politik kekuasaan sentralistik pemerintahan pra-reformasi, dan konflik komunal antarkelompok etnis di Kalimantan dianggap erat hubungannya dengan perilaku psiko-sosial berprasangka (prejudice) dan stereotip masyarakat etnis di Kalimantan Barat. Perilaku membenci (prejudice) dan bias anggapan (stereotip) terhadap kelompok-kelompok lain ini cenderung menghambat percepatan pembangunan sosial masyarakat, apalagi jika perilaku ini terjadi di sekolah sebagai salah satu lembaga pelopor pengembang nilai, ilmu pengetahuan, sikap, dan perilaku.

Sekolah, selain sebagai lembaga pengembangan intelektual kognitif siswa, mestinya juga berperan sebagai lembaga pengembangan nilai-nilai kemasyarakatan yaitu perdamaian, toleransi, hak asasi manusia, dan demokrasi dalam sikap dan perilaku peserta didik, sebut saja sebagai pendidikan untuk perdamaian (Malti, 2011; Castro \& Galace, 2010; Wessells, 1994). Tuntutan ini bersifat mendesak, terutama ditujukan kepada lembaga pendidikan atau sekolah-sekolah di wilayah pascakonflik komunal di Kalimantan Barat, khususnya di sekolah-sekolah di Kota Pontianak sebagai wilayah migrasi penduduk dari pedalaman kabupaten pada peristiwa konflik antarkelompok etnis sebanyak dua belas kali sejak tahun 1963. Satu kali diantaranya melibatkan kelompok etnis Dayak dan Tionghoa, sepuluh kali melibatkan kelompok etnis Dayak dan Madura, dan satu kali terakhir tahun 1999 melibatkan kelompok etnis Melayu dan Madura.

Menurut Djajadi (2004), ada tiga kali peristiwa kekerasan antaretnis di Kalimantan Barat bersifat kolosal, selektif, dan indiskriminatif yaitu pada tahun 1967 (Dayak-Tionghoa), 1997 (Dayak Madura), dan 1999 (Melayu-Madura). Bersifat kolosal karena melibatkan jumlah pelaku yang sangat besar, jangka waktu yang cukup lama, lokasi rambahan kekerasan sangat luas, dan jumlah korban yang sangat banyak. Bersifat selektif karena menyasar satu kelompok etnis, dan indriskriminatif karena semua individu anggota kelompok etnis menjadi sasaran kekerasan. Sebagian besar korban pindah ke Pontianak, ibu kota provinsi Kalimantan Barat, sebagai wilayah yang dianggap relatif aman dari ancaman kekerasan fisik. Namun peristiwa perang ini membawa kenangan pahit bersama (collective memory) oleh pelaku dan terutama korban dan sukar untuk dilupakan begitu saja, membangun pola berpikir 'pelaku-korban', hingga 'kitamereka' dalam hubungan sosial antarkelompok. Upaya-upaya rekonsiliasi telah dilakukan berupa pertemuan-pertemuan musyawarah antarkelompok, pemberdayaan ekonomi masyarakat, hingga penerapan sistim berbagi jabatan politik berdasarkan orientasi kesukuan, sejauh ini telah dapat mengurangi sedikit ketegangan, namun pada bidang strategis pendidikan upaya ini belum maksimal digalakkan.

Sejarah kehidupan sosial yang pincang pada masa lalu ini telah menampilkan profil dan karakter sekolah eksklusif, mengelompok, berorientasi pada etnis dan agama atau disebut secara teknis sebagai sekolah segregasi etno-religi/SE-R (ethno-religio segregated schools/E-RS). Empat sekolah swasta secara khas menampilkan profil siswa dominan etnis dan agama homogen: SMA Sultan Syarif Abdurrahman, sebagai sekolah dominan kelompok etnis Melayu (Islam); SMA Yayasan Pendidikan Kristen (YPK), dominan Dayak (Katolik); SMA Kristen Immanuel, Tionghoa (Kristen, Katolik, Konghucu, dan Budha); dan Madrasah Aliyah Swasta (MAS) Al-Anwar, Madura (Islam). Hasil survey awal penelitian ditemukan bahwa sifat mengelompok ini disebabkan oleh faktor ikatan etnis-agama, sosialekonomi, jaringan (network), komunal, dan tempat tinggal-sekolah. Dari lima faktor ini, faktor ikatan etnis-agama sangat berpengaruh dalam pembentukan sikap dan perilaku berprasangka (prejudice) dan berstereotif siswa (ingroup) terhadap kelompok etnis-agama lain yang berbeda (outgroup).

Faktor ikatan etnis-agama ini bukan sekedar kebetulan. Etnisitas dan keyakinan keagamaan adalah dua orientasi berbeda 
yang dianggap homogin di dalam masyarakat Kalimantan Barat dibandingkan dengan wilayah-wilayah lain di Kalimantan (Trijono, et al, 2004; Jamal \& Pahler, 2002; Kivimaki, 2002; Nursalim, 2002). Anggota kelompok etnis tidak dipisahkan dari identitas etnis dan agama yang dipeluknya. Etnis Melayu dipandang sebagai kelompok masyarakat yang tidak hanya memiliki kriteria sosial-budaya Melayu atau ke-Melayuan, tetapi juga beragama Islam. Etnis Dayak sebagai Dayak-Kristen - sebutan Kristen dalam pandangan masyarakat Melayu mengacu pada agama Nasrani (Katolik dan Protestan/Kristen). Etnis Tionghoa sebagai Tionghoa - Konghucu (juga dalam pandangan masyarakat Melayu). Etnis Tionghoa juga beragama Nasrani dan Budha selain Konghucu. Etnis Madura sebagai Madura-Islam. Identitas ganda ini sebagai fakta sosial sekaligus sebagai 'jembatan rapuh' untuk menuju kehidupan masyarakat yang harmonis dan damai. Konflik individual yang masif melibatkan dua orang anggota etnis yang berbeda cenderung dipersepsi sebagai konflik antaretnis dan antaragama. Dengan demikian kondisi sekolah yang mengelompok berdasarkan orientasi etnis-agama (E-RS) dikhawatirkan akan memperkuat sinyalemen dan kecenderungan konflik beridentitas ganda ini. Semestinya pembangunan masyarakat agar lebih makmur dan sejahtera membutuhkan sumber sosial berupa kerja sama sosial antarkelompok dan golongan, saling pengertian, dan saling menerima segala perbedaan.

Penelitian ini bertujuan untuk memetakan (mapping) perilaku berkelompok siswa di sekolah berdasarkan etnis-agama di empat sekolah kasus yang ditemukan dari studi awal penelitian. Pandangan kelompok etnisagama terhadap kelompok diri (ingroup) dan terhadap kelompok lain (outgroup) yang berbeda dan kuat-lemahnya hubungan antarkelompok diteliti pada tahap pertama (penelitian). Solusi terhadap kondisi ini diupayakan dengan merekonstruksi (pengembangan) konsep-konsep yang ditawarkan di lapangan menjadi model pendidikan multikultural yang cocok diterapkan untuk me- ngurangi tingkat prasangka (prejudice) dan stereotip antarkelompok etnis-agama di lembaga pendidikan di Kota Pontianak.

\section{Metode Penelitian}

Pendekatan penelitian campuran kulitatif-kuantitatif model Creswell (1994) dilakukan pada tahap pertama (tahap penelitian). Tahap kedua (tahap pengembangan) berisikan kegiatan perancangan model yang menghasilkan produk penelitian berupa rekomendasi akademis untuk sumber masukan kebijakan pendidikan di Kota Pontianak. Tahap kedua menggunakan pendekatan diskusi kelompok terbatas (Focus Group Discussion/ FGD) dengan anggota kelompok pakar, akademisi, dan praktisi pendidikan.

Penelitian awal dilakukan dengan pendekatan kualitatif untuk merumuskan masalah dan menentukan fokus penelitian. Semua rangkaian kegiatan pada survey adalah less dominant kualitatif dibandingkan dengan rangkaian kegiatan dominant kuantitatif berikutnya berupa perancangan prosedur penetapan subjek penelitian, perancangan angket, pengambilan data, dan analisis data. Fokus penelitian pada survey digali melalui tahapan atau siklus model Stake (McMillan \& Schumacher, 2001; Stark \& Thomas, 1994; Guba \& Lincoln, 1981; Worthen \& Sanders, 1981; dan Kaufman \& Thomas, 1980), dimulai dengan wawancara informal dengan partisipan (siswa, orang tua siswa, guru, kepala sekolah, kepala dan staf dinas pendidikan, ketua adat, dan dosen) hingga penetapan fokus penelitian. Tujuan wawancara ini adalah untuk menumbuhkan perhatian partisipan terhadap permasalahan yang sedang diminati, serta menggali, sekaligus mempersempit fokus penelitian.

Fokus penelitian diarahkan pada pola dan tingkat kuat-lemahnya hubungan antarkelompok etnis-agama di sekolah-sekolah kasus (E-RS) dengan mengukur tinggi-rendahnya tingkat prasangka (prejudice) dan stereotif siswa terhadap siswa lain yang berbeda etnis-agama. Sampel ditentukan secara purposif berjumlah $573(70,3 \%)$ valid dari jumlah sampel awal 815 siswa kelas 1, 2, dan 
3 dari empat sekolah yang diteliti. Angket berskala Likert dimodifikasi menjadi dua objek amatan: pernyataan tentang tingkat kesukaan terhadap masing-masing etnis (Melayu, Dayak, Madura, dan Tionghoa) dan agama Islam, Nasrani (Katolik dan Kristen/Protestan), Konghucu, dan Budha] dengan rentang kualitas sangat tidak suka (1), tidak suka (2), biasa saja (3), suka (4), dan sangat suka (5) untuk mengukur prasangka (prejudice); dan pernyataan alasan pada masing-masing item pernyataan. Pernyataan alasan menghendaki responden untuk menyebutkan anggapan mereka tentang masing-masing kelompok etnis dan agama untuk mengukur stereotip.

Tingkat prasangka kelompok terhadap kelompok etnis-agama diri dan kelompok etnis-agama lain pertama diukur persentase rata-ratanya dengan program analisis excel, kemudian dilanjutkan dengan analisis dan uji statistik $F$ untuk menentukan tingkat signifikansi dan probabilitasnya $(p)$. Semakin kecil persentase rata-rata kesukaan $(<50 \%)$, semakin tinggi tingkat berprasangka (prejudice); sebaliknya semakin besar $(>50 \%)$ semakin lemah prasangka atau semakin tinggi ikatan sosial antarkelompok. Besar persentase ini kemudian disandingkan dengan besar nilai indeks $F$ dan $p$ sebagai bagian uji validitas data.

Pernyaatan alasan positif $(+)$ seperti ramah, penolong, dan jujur, dan negatif (-) seperti sombong, pembohong, dan jorok masingmasing individu ditabulasi, kemudian dijumlahkan menjadi pernyataan kelompok, dan akhirnya ditentukan kecenderungan positif $(+)$ atau negatif $(-)$ berdasarkan selisih persentasenya. Anggapan cenderung baik (stereotip positif) jika selisih jumlah persentase variasi ungkapan baik atau positif melebihi persentase anggapan buruk yang disebutkan, demikian sebaliknya cenderung buruk (stereotif negatif) jika ungkapan buruk atau negatif lebih besar.

Hasil analisis data digunakan untuk menjawab pertanyaan penelitian: (1) pandangan dan sikap antarkelompok etnisagama, dan (2) kuat-lemah hubungan antarkelompok etnis-agama. Jawaban terhadap kedua pertanyaan ini akan menghasilkan rumusan pola-pola hubungan sosial antarkelompok dan status kondusifitas multikulturalisme di sekolah kasus. Model untuk perbaikan kondisi dirancang dan diuji dalam diskusi kelompok terbatas (FGD). Model dibangun dari konsep-konsep pendidikan multikultural yang telah ada dan disesuaikan dengan hasil temuan penelitian.

\section{Hasil Penelitian dan Pembahasan}

Prasangka (Prejudice) Etnis Antarkelompok Etnis

Hasil pengukuran menunjukkan pasangan kelompok etnis yang memiliki tingkat saling berprasangka (prejudice) tinggi adalah Dayak dan Madura. Tingkat prasangka (prejudice) kelompok etnis Dayak terhadap Madura adalah 1,8895 pada skala atau $37,79 \%$. Sebaliknya kelompok etnis Madura terhadap Dayak 2,1965 (43,93\%) Tampak juga adanya kecenderungan sikap menyukai etnis diri lebih tinggi (etno-sentrisme) pada masing-masing kelompok etnis, berprasang$\mathrm{ka}$ (prejudice) cenderung sangat rendah pada kelompok etnis diri (ingroup), namun tinggi pada kelompok etnis lain (outgroup). Prasangka (prejudice) kelompok etnis Melayu terhadap etnis Melayu sebesar 4,3470 (86,94\%), Dayak-Dayak, 4,5140 (90,28\%); MaduraMadura, 4,4750 (89,50\%); Tionghoa-Tionghoa, 4,0415 (80,83\%). Secara resiprokal prasangka (prejudice) kelompok etnis Melayu terhadap kelompok etnis Madura (Me-Ma) 2,625 (52,50\%), lebih tinggi dibandingkan sebaliknya Madura terhadap Melayu (MaMe) 3,5720 (71,44\%). Pola relasi serupa yang lain dapat dilihat pada Gambar 1.

Hubungan antarkelompok etnis Melayu-Madura tampak unik bagaikan ikatan benci-cinta (avoidance-approach), tampak dari perbedaan skala dan persentase rata-rata yang berkebalikan. Hubungan Melayu-Tionghoa justru sebaliknya. Kelompok etnis Melayu menyukai namun Melayu sebaliknya relatif kurang disukai oleh pihak Tionghoa, seperti hubungan cinta-benci (approach-avoidance). Hubungan Melayu-Dayak tampak moderat. Kelompok etnis Melayu, sedikit mendapat tempat di hati masyarakat Dayak, 
lebih dari sebaliknya yang dilakukan Melayu terhadap Dayak.

Hubungan antarkelompok etnis Dayak-Madura tampak unik, sekaligus beresiko (conflicting pair) berdasarkan besaran skala dan persentase rata-rata. Hubungan kelompok etnis lain (Melayu dan Tionghoa) terhadap Madura juga tampak sama beresiko, menjadikan kelompok etnis Madura cenderung sebagai objek target konflik. Kelompok etnis Tionghoa, berdasarkan besaran skala dan persentase rata-rata hubungan resiprokal justru sebaliknya. Kelompok etnis Tionghoa tampak relatif disukai oleh ketiga kelompok etnis yang lain, menjadikan Tionghoa lebih populer (appealing group) di antara empat kelompok etnis yang diteliti. Sikap kelompok etnis Tionghoa terhadap kelompok-kelompok etnis yang lain lebih bervariasi, moderat terhadap Melayu, berprasangka (prejudice) sedikit lebih tinggi ter- hadap Madura, dan relatif menyukai kelompok etnis Dayak. Pasangan kelompok etnis Dayak-Tionghoa tampak saling mendukung (approach-approach), menjadikan pasangan ini lebih kompak bagaikan pasangan 'bulan madu' (boneymoon), berdasarkan dukungan sejarah kehidupan sosial masa lalu masyarakat Dayak dan Tionghoa di wilayah pedalaman Kalimantan Barat.

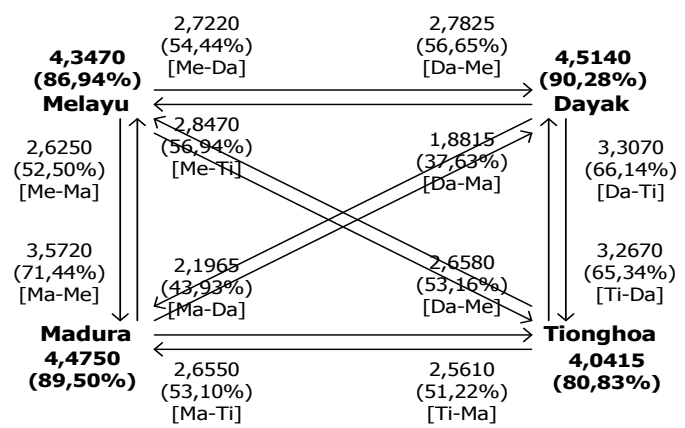

Gambar 1. Pola Relasi Antarkelompok Etnis

Tabel 1. Prasangka (Prejudice) terhadap Etnis Antarsekolah-Antarkelompok: Tingkat Signifikansi Berdasarkan Indeks Uji F dan Probabilitas $(p) \alpha=0,05$

\begin{tabular}{|c|c|c|c|c|c|}
\hline Sekolah & Kel. & Kelas & $\mathrm{F}$ & $\mathrm{p}$ & Ket. \\
\hline \multirow{3}{*}{ SMA Sultan Syarif Abdurrahman } & \multirow{3}{*}{ Melayu-Islam } & 1 & 11,00 & $0,0033(\mathrm{p}<0,05)$ & Sig. \\
\hline & & 2 & 3,15 & $0,0645(p>0,05)$ & Tdk.Sig. \\
\hline & & 3 & 3,51 & $0,0280(\mathrm{p}<0,05)$ & Sig. \\
\hline \multirow{3}{*}{ MAS Al-Anwar } & \multirow{3}{*}{ Madura-Islam } & 1 & 70,17 & $0,0001(\mathrm{p}<0,05)$ & Sig. \\
\hline & & 2 & 46,96 & $0,0011(\mathrm{p}<0,05)$ & Sig. \\
\hline & & 3 & 67,10 & $0,0001(\mathrm{p}<0,05)$ & Sig. \\
\hline \multirow{6}{*}{ SMA Yayasan Pendidikan Kristen (YPK) } & \multirow{3}{*}{ Dayak-Kat. } & 1 & 32,50 & $0,0001(\mathrm{p}<0,05)$ & Sig. \\
\hline & & 2 & 55,01 & $0,0001(\mathrm{p}<0,05)$ & Sig. \\
\hline & & 3 & 23,53 & $0,0001(\mathrm{p}<0,05)$ & Sig. \\
\hline & \multirow{3}{*}{ Dayak-Pro. } & 1 & 36,95 & $0,0001(\mathrm{p}<0,05)$ & Sig. \\
\hline & & 2 & 42,52 & $0,0001(\mathrm{p}<0,05)$ & Sig. \\
\hline & & 3 & 15,77 & $0,0001(\mathrm{p}<0,05)$ & Sig. \\
\hline \multirow{12}{*}{ SMA Kristen Immanuel } & \multirow{3}{*}{ Tiong.-Kat. } & 1 & 21,96 & $0,0001(\mathrm{p}<0,05)$ & Sig. \\
\hline & & 2 & 30,46 & $0,0001(\mathrm{p}<0,05)$ & Sig. \\
\hline & & 3 & 37,19 & $0,0080(\mathrm{p}<0,05)$ & Sig. \\
\hline & \multirow{3}{*}{ Tiong.-Pro. } & 1 & 44,11 & $0,0001(\mathrm{p}<0,05)$ & Sig. \\
\hline & & 2 & 34,54 & $0,0001(\mathrm{p}<0,05)$ & Sig. \\
\hline & & 3 & 72,33 & $0,0001(\mathrm{p}<0,05)$ & Sig. \\
\hline & \multirow{3}{*}{ Tiong.- Kong. } & 1 & 12,90 & $0,0001(\mathrm{p}<0,05)$ & Sig. \\
\hline & & 2 & 4,85 & $0,0107(\mathrm{p}<0,05)$ & Sig. \\
\hline & & 3 & 7,19 & $0,0028(\mathrm{p}<0,05)$ & Sig. \\
\hline & \multirow{3}{*}{ Tiong.-Bud. } & 1 & 29,67 & $0,0001(\mathrm{p}<0,05)$ & Sig. \\
\hline & & 2 & 17,20 & $0,0001(\mathrm{p}<0,05)$ & Sig. \\
\hline & & 3 & 9,41 & $0,0001(\mathrm{p}<0,05)$ & Sig. \\
\hline
\end{tabular}


Tabel 2. Prasangka (Prejudice) terhadap Etnis Antarkelas-Semua Kelompok: Tingkat Signifikansi Berdasarkan Indeks Uji F dan Probabilitas $(p) \alpha=0,05$

\begin{tabular}{cccc}
\hline Kelas & $\mathrm{F}$ & $p$ & Keterangan \\
\hline 1 & 0,43 & 0,8834 & Tidak signifikan \\
2 & 1,21 & 0,2971 & Tidak signifikan \\
3 & 1,41 & 0,2005 & Tidak signifikan \\
\hline
\end{tabular}

Tabel 3. Prasangka (Prejudice) terhadap Etnis Seluruh Siswa-Semua Kelompok: Tingkat Signifikansi Berdasarkan Indeks Uji F dan Probabilitas $(p) \alpha=0,05$

\begin{tabular}{cccc}
\hline Kelas & $\mathrm{F}$ & $p$ & Keterangan \\
\hline $1,2,3$ & 0,83 & 0,5588 & Tidak Signifikan \\
\hline
\end{tabular}

Hubungan antarkelompok etnis juga dapat dilihat dari hasil uji $\mathrm{F}$ dan probabilitas $(p)$ yang mengungkap tingkat perbedaan tanggapan siswa dari masing-masing kelompok dan sekolah terhadap perbedaan etnis yang ada. Siswa pada subkategori antarsekolab-antarkelompok secara spesifik menunjukkan sikap yang lebih konservatif terhadap pluralitas etnis. Perbedaan etnis yang ada secara tegas dianggap memang berbeda, signifikan di hampir seluruh tingkatan kelas di tiap-tiap sekolah, kecuali di kelas 2 siswa kelompok etnis Melayu di SMA Sultan Syarif Abdurrahman (lihat Tabel 1). Sikap siswa menjadi lebih liberal pada tampilan subkategori antarkelas-semua kelompok. (Tabel 2) dan subkategori selurub siswa-semua kelompok (Tabel 3). Siswa lebih tebuka terhadap perbedaan dan cenderung memperlakukan perbedaan kelompok etnis yang ada relatif sama. Sikap ini sekaligus menunjukkan bukti bahwa perilaku mengelompok secara eksklusif cenderung membangun sikap berprasangka (prejudice) lebih tinggi dibandingkan dengan membaur.

\section{Prasangka (Prejudice) Agama Antarkelompok Etnis}

Tabel 4. Prasangka (Prejudice) Terhadap Agama Antarsekolah-Antarkelompok: Tingkat Signifikansi Berdasarkan Indeks Uji F dan Probabilitas $(p) \alpha=0,05$

\begin{tabular}{|c|c|c|c|c|c|}
\hline Sekolah & Kel. & Kelas & $\mathrm{F}$ & $\mathrm{p}$ & Ket. \\
\hline \multirow{3}{*}{ SMA Sultan Syarif Abdurrahman } & \multirow{3}{*}{ Melayu-Islam } & 1 & 24,50 & $0,0013(\mathrm{p}<0,05)$ & Sig. \\
\hline & & 2 & 39,00 & $0,0001(\mathrm{p}<0,05)$ & Sig. \\
\hline & & 3 & 17,27 & $0,0001(\mathrm{p}<0,05)$ & Sig. \\
\hline \multirow{4}{*}{ MAS Al-Anwar } & \multirow{4}{*}{ Madura-Islam } & 1 & 239,81 & $0,0001(\mathrm{p}<0,05)$ & Sig. \\
\hline & & 2 & 131,56 & $0,0001(\mathrm{p}<0,05)$ & Sig. \\
\hline & & 3 & 154,64 & $0,0001(\mathrm{p}<0,05)$ & Sig. \\
\hline & & 1 & 23,36 & $0,0001(\mathrm{p}<0,05)$ & Sig. \\
\hline \multirow{5}{*}{ SMA Yayasan Pendidikan Kristen (YPK) } & \multirow[t]{2}{*}{ Dayak-Kat. } & 2 & 22,88 & $0,0001(\mathrm{p}<0,05)$ & Sig. \\
\hline & & 3 & 15,05 & $0,0001(\mathrm{p}<0,05)$ & Sig. \\
\hline & \multirow{4}{*}{ Dayak-Pro. } & 1 & 24,75 & $0,0001(\mathrm{p}<0,05)$ & Sig. \\
\hline & & 2 & 26,36 & $0,0001(\mathrm{p}<0,05)$ & Sig. \\
\hline & & 3 & 15,20 & $0,0001(\mathrm{p}<0,05)$ & Sig. \\
\hline \multirow{12}{*}{ SMA Immanuel } & & 1 & 23,48 & $0,0001(\mathrm{p}<0,05)$ & Sig. \\
\hline & \multirow[t]{2}{*}{ Tiong.-Kat. } & 2 & 23,23 & $0,0001(\mathrm{p}<0,05)$ & Sig. \\
\hline & & 3 & 4,42 & $0,0080(\mathrm{p}<0,05)$ & Sig. \\
\hline & \multirow{4}{*}{ Tiong.-Pro. } & 1 & 80,78 & $0,0001(\mathrm{p}<0,05)$ & Sig. \\
\hline & & 2 & 42,43 & $0,0001(\mathrm{p}<0,05)$ & Sig. \\
\hline & & 3 & 21,52 & $0,0001(\mathrm{p}<0,05)$ & Sig. \\
\hline & & 1 & 13,78 & $0,0001(\mathrm{p}<0,05)$ & Sig. \\
\hline & \multirow[t]{2}{*}{ Tiong.-Kong. } & 2 & 5,06 & $0,0040(\mathrm{p}<0,05)$ & Sig. \\
\hline & & 3 & 9,03 & $0,0002(\mathrm{p}<0,05)$ & Sig. \\
\hline & \multirow{3}{*}{ Tiong.- Bud. } & 1 & 16,92 & $0,0001(\mathrm{p}<0,05)$ & Sig. \\
\hline & & 2 & 1,33 & $0,2656(\mathrm{p}>0,05)$ & Tdk.Sig. \\
\hline & & 3 & 1,77 & $0,1452(\mathrm{p}>0,05)$ & Tdk.Sig. \\
\hline
\end{tabular}


Prasangka (prejudice) kelompok etnis terhadap agama yang umumnya dipeluk oleh masing-masing kelompok etnis sangat khas. Masing-masing kelompok secara ketat dan stabil memandang agama kelompoknya lebih baik, baik dalam bentuk berkelompok secara eksklusif, maupun membaur (lihat Tabel 4-6). Hal ini berbeda dengan orientasi keetnisan yang sedikit lebih lentur pada kondisi membaur.

Tabel 5. Prasangka (Prejudice) terhadap Agama Antarkelas-Semua Kelompok Tingkat Signifikansi Berdasarkan Indeks Uji F dan Probabilitas $(p) \alpha=0,05$

\begin{tabular}{cllc}
\hline Kelas & $F$ & $p$ & Keterangan \\
\hline 1 & 3,16 & 0,0026 & Signifikan \\
2 & 4,13 & 0,0002 & Signifikan \\
3 & 1,42 & 0,1949 & Tidak signifikan \\
\hline
\end{tabular}

Tabel 6. Prasangka (Prejudice) terhadap Agama Seluruh Siswa-Semua Kelompok Tingkat Signifikansi Berdasarkan Indeks Uji F dan Probabilitas $(p) \alpha=0,05$

\begin{tabular}{cccc}
\hline Kelas & $\mathrm{F}$ & $p$ & Keterangan \\
\hline $1,2,3$ & 4,87 & 0,0001 & Signifikan \\
\hline
\end{tabular}

Sikap yang lebih lentur terhadap agama ditunjukkan oleh subkelompok etnis Tionghoa-Budha kelas 2 dan 3 pada subkategori antarsekolah-antarkelompok dan seluruh siswa kelas 3 pada subkategori antarkelas-semua kelompok. Namun secara keseluruhan sikap siswa stabil dan konsisten menganggap agama sebagai wilayah privat, masing-masing berbeda, dan masing-masing agama tidak dapat direduksi menjadi keyakinan bersama.

\section{Stereotip Etnis Antarkelompok Etnis}

Selisih persentase terbesar positif $(+)$ atau negatif (-) menunjukkan kecenderungan anggota kelompok etnis menganggap kelompok diri (ingroup) atau kelompok lain (outgroup) lebih baik atau lebih buruk berdasarkan rekapitulasi ungkapan baik/positif, seperti rajin dan ramab; dan ungkapan bu- ruk/negatif, seperti pemalas dan sombong. Tabel 7 berikut ini menggambarkan pola hubungan antaretnis berdasarkan anggapan (stereotip) yang disampaikan siswa.

Suatu hal yang wajar jika anggota kelompok etnis memandang positif terhadap etnisnya masing-masing dengan syarat jika sikap dan tindakannya tidak merendahkan kelompok lain. Hubungan antarkelompok yang diharapkan adalah jika kelompok-kelompok tersebut saling memandang positif $(++)$, seperti yang ditampilkan oleh kelompok etnis Dayak dan Tionghoa. Kedua kelompok ini tampak saling mendukung, dengan demikian lebih berpeluang menciptakan perdamaian. Tantangan yang lebih besar ke arah ini adalah memperbaiki hubungan yang tampak kurang harmonis antarkelompok etnis Me-layu-Tionghoa $(-+)$, Melayu - Madura (+ -), terutama sekali Melayu-Dayak (- -) dan Dayak-Madura (- -).

Stereotip positif $(+)$ atau negatif $(-)$ etnis seperti yang diperlihatkan pada tabel mendukung bukti bahwa kecenderungan sikap berprasangka (prejudice) adalah selaras dengan sikap berstereotip antarkelompok etnis. Sikap cenderung tidak menyukai memang sejatinya dibangun oleh anggapananggapan buruk/ negatif terhadap pihak lain. Pola perilaku ini dirumuskan oleh Myers (2007) dan Stephan \& Stephan (1985) dengan ABC, affective (A), behavior (B), dan cognitive (C). Suka-tidak suka terhadap suatu objek benda, ide, atau orang (affective) A); adanya kecenderungan bertindak diskriminatif terhadapnya (behavior/B); karena didasari oleh anggapan subjektifnya (cognitive/C). Seseorang membenci orang lain (A), menghindarinya (B), karena menganggap orang lain itu kejam (C). Rumus perilaku ini juga dapat dipakai untuk memprediksi perilaku seseorang terhadap etnis atau agama. Seseorang membenci etnis atau agama lain, cenderung menghindari atau bergaul dengannya, karena menganggap etnis atau agama orang lain itu kejam. Logika negatif linear ini yang akan dirubah menjadi perilaku sebaliknya dengan pendidikan multikultural: menyukai pihak lain, bersahabat dengannya, karena ada banyak sisi positif darinya yang menarik untuk dikenal. 
Tabel 7. Stereotip Etnis Antarkelompok Etnis

\begin{tabular}{|c|c|c|c|c|}
\hline Etnis & Melayu & Dayak & Tionghoa & Madura \\
\hline \multirow[t]{2}{*}{ Melayu } & $\begin{array}{c}+(\mathbf{9 3 , 7 5 \% )} \\
-(6,25 \%)\end{array}$ & $\begin{array}{l}+(36,84 \%) \\
-(\mathbf{6 3 , 1 6 \% )}\end{array}$ & $\begin{array}{l}+(64,29 \%) \\
-(35,71 \%)\end{array}$ & $\begin{array}{r}+(22,73 \%) \\
-(77,27 \%)\end{array}$ \\
\hline & + & $\begin{array}{c}- \\
- \\
+(30,89 \%) \\
-(\mathbf{6 9 , 1 1 \% )}\end{array}$ & $\begin{array}{c}-\quad+ \\
+(31,14 \%) \\
-(\mathbf{6 8 , 8 6 \% )}\end{array}$ & $\begin{array}{c}+\quad- \\
+(66,06 \%) \\
-(33,94 \%)\end{array}$ \\
\hline \multirow[t]{2}{*}{ Dayak } & $\begin{array}{l}+(30,89 \%) \\
-(\mathbf{6 9 , 1 1 \% )}\end{array}$ & $\begin{array}{c}+(\mathbf{9 5 , 4 3 \% )} \\
-(4,57 \%)\end{array}$ & $\begin{array}{c}+(\mathbf{6 9}, \mathbf{5 1} \% \mathbf{)} \\
-(30,49 \%)\end{array}$ & $\begin{array}{l}+(2,49 \%) \\
-(\mathbf{9 7 , 5 1 \% )}\end{array}$ \\
\hline & $\begin{array}{c}-\quad- \\
+(36,84 \%) \\
-(63,16 \%)\end{array}$ & + & $\begin{array}{c}+\quad+ \\
+(79,40 \%) \\
-(20,60 \%)\end{array}$ & $\begin{array}{c}- \\
+(9,63 \%) \\
-(90,37 \%)\end{array}$ \\
\hline \multirow[t]{3}{*}{ Tionghoa } & $\begin{array}{l}+(31,14 \%) \\
-(\mathbf{6 8 , 8 6 \% )}\end{array}$ & $\begin{array}{c}+(\mathbf{7 9 , 4 0 \% )} \\
-(20,60 \%)\end{array}$ & $\begin{array}{c}+(86,4 \%) \\
-(13,59)\end{array}$ & $\begin{array}{l}+(19,75 \%) \\
-(\mathbf{8 0 , 2 5 \% )}\end{array}$ \\
\hline & $+\quad-$ & $+\quad+$ & + & $+/-$ \\
\hline & $\begin{array}{c}+(\mathbf{6 4 , 2 9 \%}) \\
-(35,71 \%)\end{array}$ & $\begin{array}{c}+(\mathbf{6 9}, \mathbf{5 1} \% \mathbf{)} \\
-(30,49 \%)\end{array}$ & & $\begin{array}{l}+(50,00 \%) \\
-(50,00 \%)\end{array}$ \\
\hline \multirow[t]{3}{*}{ Madura } & $\begin{array}{c}+(\mathbf{6 6}, 06 \%) \\
-(33,94 \%)\end{array}$ & $\begin{array}{l}+(9,63 \%) \\
-(\mathbf{9 0 , 3 7 \% )}\end{array}$ & $\begin{array}{l}+(50,00 \%) \\
-(50,00 \%)\end{array}$ & $\begin{array}{c}+(93,63 \%) \\
-(6,37 \%)\end{array}$ \\
\hline & $-\quad+$ & $-\quad-$ & $-+/-$ & + \\
\hline & $\begin{array}{l}+(22,73 \%) \\
-(77,27 \%)\end{array}$ & $\begin{array}{l}+(2,49 \%) \\
-(\mathbf{9 7 , 5 1 \% )}\end{array}$ & $\begin{array}{l}+(19,75 \%) \\
-(\mathbf{8 0 , 2 5 \% )}\end{array}$ & \\
\hline
\end{tabular}

Stereotif Agama Antarkelompok Etnis

Telah disebutkan sebelumnya bahwa etnis dan agama sebagai identitas ganda merupakan identifikasi sosial yang khas di Kalimantan Barat. Identitas ganda etnisagama ini sering menyulitkan usaha-usaha perdamaian jika terjadi perselisihan antar- kelompok. Stereotip terhadap agama, seperti tampak pada Tabel 8 , sebenarnya sangat relatif bahkan subjektif sifatnya mengingat peran psikologis-sosial identitas ganda ini. Berstereotip positif atau negatif terhadap agama juga sebenarnya berstereotip positif atau negatif terhadap etnis sekaligus.

Tabel 8. Stereotip Agama Antarkelompok Etnis

\begin{tabular}{|c|c|c|c|c|c|c|}
\hline $\begin{array}{l}\text { Agama } \\
\text { Etnis }\end{array}$ & Islam & Kristen & Konghucu & Katolik & Protestan & Budha \\
\hline Melayu & $\begin{array}{l}+ \\
+(100 \%) \\
-(00,00 \%)\end{array}$ & $\begin{array}{l}- \\
+(16,67 \%) \\
-(\mathbf{8 3 , 3 3 \% )}\end{array}$ & $\begin{array}{l}- \\
+(11,11 \%) \\
-(\mathbf{8 8 , 8 9 \% )}\end{array}$ & & & \\
\hline Madura & $\begin{array}{l}+ \\
+(100 \%) \\
-(00,00 \%)\end{array}$ & $\begin{array}{l}- \\
+(17,76 \%) \\
-(82,24 \%)\end{array}$ & $\begin{array}{l}- \\
+(8,43 \%) \\
-(\mathbf{9 1 , 5 7 \% )}\end{array}$ & & & \\
\hline Dayak & $\begin{array}{l}- \\
+(23,40 \%) \\
-(\mathbf{7 6 , 6 0 \% )}\end{array}$ & & $\begin{array}{l}- \\
+(46,58 \%) \\
-(53,42 \%)\end{array}$ & $\begin{array}{l}+ \\
+(\mathbf{9 2 , 8 6 \% )} \\
-(7,14 \%)\end{array}$ & $\begin{array}{l}+ \\
+(89,32 \%) \\
-(10,68 \%)\end{array}$ & $\begin{array}{l}- \\
+(42,53 \%) \\
-(57,47 \%)\end{array}$ \\
\hline Tionghoa & $\begin{array}{l}- \\
+(13,00 \%) \\
-(87,00 \%)\end{array}$ & & $\begin{array}{l}+ \\
+(69,42 \%) \\
-(30,58 \%)\end{array}$ & $\begin{array}{l}+ \\
+(84,77 \%) \\
-(15,23 \%)\end{array}$ & $\begin{array}{l}+ \\
+(84,15 \%) \\
-(15,85 \%)\end{array}$ & $\begin{array}{l}+ \\
+(82,20 \%) \\
-(17,80 \%)\end{array}$ \\
\hline
\end{tabular}


Kelompok etnis Melayu dan Madura mengikat diri lebih kuat pada agama Islam, tampak dari anggapan positif mereka terhadap agama ini $(100 \%)$. Pada Dayak pandangan terhadap Islam relatif sangat rendah, yaitu hanya $+23,40 \%$ atau $-76,60 \%$, demikian juga Tionghoa, hanya $+13 \%$ atau 87\%. Melayu terhadap Kristen dan Konghucu masing-masing $+16,67 \%$ atau $-83,33 \%$ dan $+11,11 \%$ atau $-88,89 \%$. Demikian juga Madura terhadap kedua agama Kristen dan Konghucu yang masing-masing dipeluk oleh sebagian besar kelompok etnis Dayak dan Tionghoa ini, hanya $+17,66 \%$ atau $82,24 \%$ dan $+8,43 \%$ atau $-91,57 \%$. Pandangan kelompok etnis Dayak terhadap agama Konghucu dan Budha sedikit lebih rendah meskipun agama ini sebagian besar dipeluk oleh kelompok etnis Tionghoa, sebagai kelompok etnis sahabat Dayak, dan memberi citranya yang lebih baik pada agama Katolik dan Kristen/Protestan. Pandangan Kelompok etnis Tionghoa terhadap agama jauh lebih liberal terhadap agama, termasuk agama yang mereka peluk, hanya kurang lebih 80-an persen saja.

\section{Sensitivitas Etnis dan Agama}

Tinggi rendah rata-rata skala dan persentase prasangka (prejudice) serta stereotip positif $(+)$ dan negatif $(-)$ terhadap etnis dan agama dari empat kelompok etnis yang diteliti juga menggambarkan tingkat sensitifitas kelompok-kelompok ini terhadap etnis dan agama. Sensitivitas etnis dan agama menunjukkan sikap dan perilaku kejiwaan dan kedalaman emosi yang memandang sejauh mana dua objek lembaga sosial dan agama ini penting dalam kehidupan seseorang atau kelompok. Tabel 9 dan 10 memperlihatkan hasil olah data tentang sikap kelompok terhadap pentingnya etnis dan agama bagi kelompoknya.

Tabel 9. Sensitivitas Kelompok Etnis terhadap Etnis

\begin{tabular}{ccc}
\hline No & Etnis & \multicolumn{2}{c}{ Sensitivitas Keetnisan } \\
\hline 1 & Dayak & $4,5140(90,28 \%)$ \\
2 & Madura & $4,4750(89,50 \%)$ \\
3 & Melayu & $4,3470(86,94 \%)$ \\
4 & Tionghoa & $4,0415(80,83 \%)$ \\
\hline
\end{tabular}

Tabel 10. Sensitivitas Kelompok Etnis terhadap Agama

\begin{tabular}{ccc}
\hline No & Etnis & Sensitivitas Keagamaan \\
\hline 1 & Melayu & $5,0000(100 \%)$ \\
2 & Madura & $4,9340(98,68 \%)$ \\
3 & Dayak & $4,2110(84,22 \%)$ \\
4 & Tionghoa & $3,5020(70,04 \%)$ \\
\hline
\end{tabular}

Etnis bagi sebagian besar anggota kelompok etnis Dayak adalah sangat penting dan utama, namun sebaliknya Melayu memandang agama jauh lebih penting daripada etnis. Kelompok etnis Madura memandang keduanya penting, tetapi sebaliknya relatif kurang begitu penting bagi Tionghoa. Dayak dengan demikian lebih sensitif terhadap segala hal yang berkaitan dengan etnisitas, Melayu lebih pada agama, Madura pada keduanya, sebaliknya Tionghoa pada hal lain selain etnis dan agama. Tipologi sensitivitas ini dapat dipakai untuk menentukan cara berkomunikasi yang tepat dan efektif terhadap masing-masing kelompok etnis guna membangun kerja sama antarkelompok.

Model Pendidikan Multikultural Konteks Sekolah E-RS

Model pendidikan multikultural pada konteks sekolah mengelompok berdasarkan etnis-agama (ethno-religio segregation/ E-RS) di Kota Pontianak adalah pendidikan yang mengendorkan tingkat prasangka (prejudice) dan stereotip negatif antarkelompok etnis-agama. Model ini dikembangkan dari konsepkonsep pendidikan multikultural lainnya, misalnya model akomodasi keragaman identitas agama, ras, etnis, dan potensi individu dari Baso (2003), Semiawan (2003), dan Bank (Hammond, 1993); keragaman budaya (cultural diversity) dan kesetaraan (equality) dari Gollnick \& Chinn (2007) dan Banks (2003, 2001); reformasi sekolah dari Fullan (1997); inklusif dari Yaqin (2006), Walker \& Dimmock (2005), dan Swetnam (2003); model integrasi dan keterwakilan dari Salomon (Beardslee, 2004); atau model tiga dimensi usaha perubahan dari Banks (Banks, 1997; Hammond, 1993), yaitu penguatan budaya 
sekolah (empowering school culture), integrasi muatan kurikulum (content integration), dan pengendoran prasangka (prejudice reduction).

Sikap berprasangka (prejudice) dan stereotip menghambat kerja sama sosial antarkelompok di dalam masyarakat, terlebih lagi jika sikap ini dibangun di sekolah, karena sekolah adalah lembaga pendidikan yang strategis dalam pembangunan masyarakat. Mengendorkan sikap ini terhadap pihak lain yang berbeda diharapkan mampu meningkatkan kualitas dan produktifitas hubungan antarkelompok, terutama kelompok-kelompok etnis yang pernah terlibat dalam konflik komunal di Kalimantan Barat di masa lalu. Hubungan yang berkualitas dan produktif adalah hubungan yang saling percaya, tenggang rasa, menghormati perbedaan, hingga bekerja sama menyelesaikan berbagai masalah sosial di masyarakat.

Perilaku mengelompok bersekolah butuh penanganan sinergis dari berbagai pihak dan dengan proses yang cukup lama. Perubahan perilaku mengelompok menjadi membaur di sekolah-sekolah negeri, misalnya, memerlukan perbaikan sistim manajemen pendidikan sekolah swasta dan negeri, kurikulum, hingga pembenahan sosial-ekonomi masyarakat. Namun jika sikap dan perilaku mengelompok memang sukar dibaurkan, atau dengan kata lain jika mengelompok berdasarkan orientasi keetnisanagama memang merupakan praktik pendidikan yang khas berdasarkan alasan-alasan psikologis-sosial dan kesejarahan maka perlu menjembatani hubungan antarkelompok yang terpisah ini dengan penanaman pandangan-pandangan positif tentang kelompok lain dan terus menumbuhkan sikap dan perilaku positif ini dengan usaha-usaha yang konstruktif. Dalam penelitian, konsep ini disebut dengan keberlainan positif-konstruktif (positive-constructive otherness). Ini adalah syarat minimal dalam pendidikan multikultural, disamping syarat lain yaitu kesetaraan, keadilan, dan keragaman, baik secara kualitas maupun kuantitas. Dalam konsep ini masing-masing pihak harus memiliki pandangan positif terhadap pihak lain. Pihak lain (other) akan dianggap memiliki keunikan, berbeda, namun penting untuk dihormati. Kehadiran pihak lain dianggap bermanfaat sekaligus sangat penting bagi keberadaan diri atau kelompok diri atau disebut dengan keberlainan (otherness). Pandangan positif ini harus ditampilkan dengan berbagai upaya penumbuhan dari pihak sekolah sebagai citra untuk menghapus pandangan-pandangan negatif yang selama ini hidup dalam alam pikiran bawah sadar masyarakat. Sikap dan perilaku kunci untuk membangun citra positif ini, berdasarkan analisis jejak alasan responden pada variabel stereotip, adalah 'ramah' atau 'keramahan.' Model 'ramah' ini pula yang dijadikan pijakan terhadap berbagai upaya sekolah membangun citra positif dan kerja sama antarkelompok ini. Upaya penumbuhan sikap dan perilaku ramah dinaungi oleh rencana aksi RAMAH, akronim dari kata ramah itu sendiri, yaitu Rencana Aksi pendidikan Multikultural Agar Harmonis. Rancangan kegiatan harus dikembangkan pada wilayahwilayah umum atau universal (inklusif) etnis dan agama semua kelompok masyarakat, bukan wilayah privat (partikular/eksklusif) yang berkaitan dengan dasar-dasar keyakinan dan tata cara ritual etnis dan keagamaan (lihat Gambar 2).

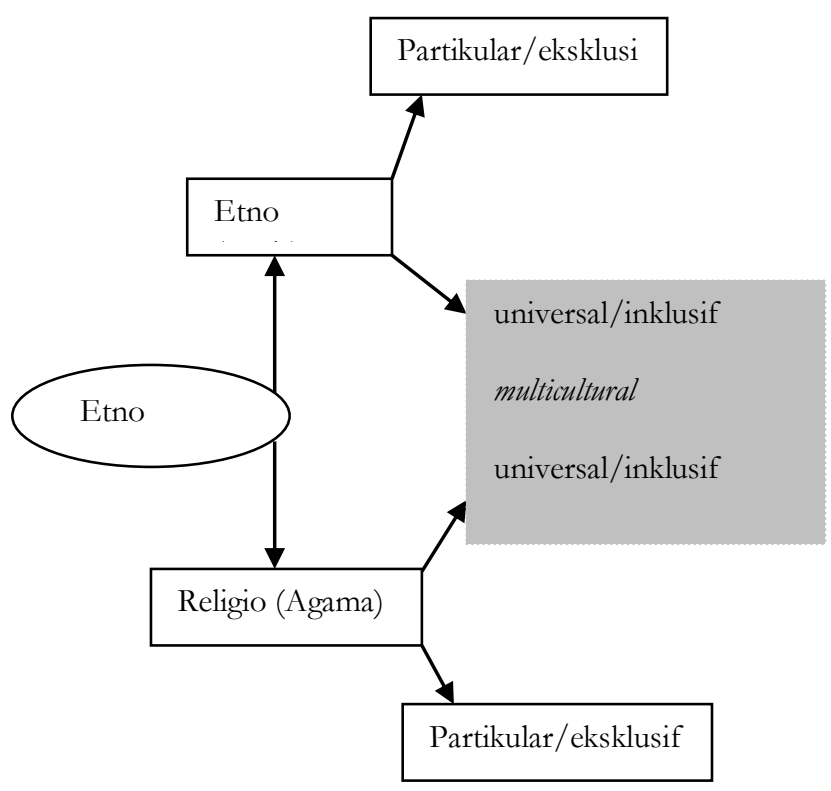

Gambar 2. Wilayah Potensial Pengembangan Pendidikan Multikultural 
Beberapa upaya potensial yang dapat menumbuhkan citra positif dan kerja sama diantaranya adalah dengan meningkatkan intensitas hubungan (kontak) antarkelompok. Kontak antarkelompok harus bersifat kooperatif dan intens dilakukan dalam bentuk kegitan-kegiatan bersama antarsekolah, seperti kemah pramuka bersama, kegiatan bhakti penanaman pohon bersama, kerja bhakti bersama membersihkan rumah ibadah, atau kunjungan bersama ke lokasi kelompok kerja masyarakat adat. Informasi yang relevan, luas, dan beragam tentang budaya, pandangan hidup, adat-istiadat dan kebiasaan kelompok harus disediakan. Lainnya adalah perbaikan muatan kurikulum; pemberdayaan guru dan staf sekolah dengan wawasan multikultural; serta perbaikan sistim evaluasi dan pemantauannya. Semuanya melibatkan aktor dari berbagai pihak dan bekerja secara sinergis untuk mencapai tujuan akhirnya, yaitu hubungan dan kehidupan sosial antarkelompok masyarakat menjadi Harmonis.

\section{Simpulan}

Prasangka (prejudice) dan stereotip antarkelompok etnis-agama berkembang dalam masyarakat etnis Melayu, Dayak, Tionghoa, dan Madura di Kota Pontianak disebakan oleh faktor sejarah sosial-politik masa lalu di Kalimantan Barat. Pendekatan diskriminatif pemerintahan kolonial, struktur politik kekuasaan sentralistik pemerintahan pra-reformasi, dan konflik komunal telah merenggangkan ikatan sosial antarkelompok masyarakat dan memupuk prasangka (prejudice) dan stereotip, membenci dan memberi sifat bias pada kelompok lain yang berbeda. Di bidang pendidikan siswa dari kelompok-kelompok etnis korban bencana sosial-politik masa lalu ini mengelompok di sekolah-sekolah swasta berdasarkan etnisagama (ethno-religio segregation/ E-RS).

Pola hubungan antarkelompok etnisagama dari E-RS ini dapat dilihat dari sikap dan perilaku berprasangka (prejudice) dan stereotip siswa terhadap kelompok etnis-agama diri (ingroup) dan kelompok etnis-agama lain (outgroup). Pola ethno-sentrisme khas terdapat pada masing-masing kelompok, yaitu adanya kecenderungan sikap untuk menaikan nilai dan harga diri kelompok, dan secara bersamaan menurunkannya pada kelompok yang lain. Hubungan kelompok etnis Melayu-Dayak, Melayu-Tionghoa, Melayu-Madura membentuk pola cinta-benci (approach-avoidance) atau benci-cinta (avoidanceapproach); Dayak-Tionghoa, saling menyukai (approach-approach), bagaikan dua kelompok berbulan madu (boney moon) yang saling mendukung; Dayak-Madura, saling membenci (avoidance-avoidance) atau cenderung berseteru (conflicting pair). Terdapat juga indikasi yang menjadikan kelompok etnis Madura sebagai target konflik dan Tionghoa sebagai etnis sanjungan.

Tinggi rendah prasangka (prejudice) dan stereotip yang pada masing-masing kelompok juga menunjukkan sensitivitas kelompok, kuat-lemahnya sikap dan perilaku kejiwaan dan kedalaman emosi yang memandang penting kehadiran lembaga etnis dan agama pada diri individu atau kelompok. Kelompok etnis Dayak sangat sensistif pada faktor etnis, Melayu sangat sensisitif pada faktor agama, Madura pada keduanya, sebaliknya Tionghoa pada faktor-faktor lain selain etnis dan agama. Efektifitas dan keberhasilan dalam membina hubungan antarkelompok dengan masing-masing kelompok ini tergantung pada kecerdasan dalam memahami dan membedakan faktor-faktor sensitivitas ini pada kelompok dalam berkomunikasi dan berinteraksi.

Sifat dan sikap ramah atau keramahan melalui pendidikan multikultural diyakini dapat mengendorkan sikap dan perilaku berprasangka (prejudice) dan stereotip antarkelompok di sekolah-sekolah E-RS. Dengan aksi RAMAH (Rencana Aksi pendidikan Multikultural Agar Harmonis) ramah atau keramahan dalam sifat dan sikap siswa dibangun melalui berbagai usaha pendidikan dan usaha sekolah, seperti pembauran (kontak) siswa pada kegiatan-kegiatan sosialkooperatif yang dirancang bersama, memuati kurikulum dan materi pengajaran dengan informasi multibudaya yang relevan, 
beragam, dan bernilai positif, terutama tentang norma dan nilai budaya dan agama kelompok etnis yang diteliti. Usaha konstruktif ini diharapkan menumbuhkan citra positif, secara bersamaan mengendorkan tingkat prasangka (prejudice) dan bias pendapat (stereotip) terhadap pihak lain yang berbeda, hingga akhirnya terjalin kerja sama dan kehidupan yang harmonis.

\section{Daftar Pustaka}

Baso, A. (2003). Demokerasi dan multikulturalisme. Diakses tanggal 25 Januari 2009, dari http://www.wahana kebangsaan.org/index.php?option= com_content\&task $=$ view\&id $=51 \&$ Ite $\underline{\operatorname{mid}=33}$

Banks, J.A. (2003). Educating global citizens in a diverse world. New Horizon for Learning. Diakses tanggal 2 Februari 2009, dari http://www.newhorizons. org/strategies/multicultural/banks $2 . h$ $\underline{\mathrm{tm}}$.

Banks, J.A. (2001). Diversity within unity: Essential principles for teaching and learning in a multicultural society. New Horizons for Learning. Diambil pada tanggal 2 Februari 2009, dari http://www.newhorizons.org/strateg ies/multicultural/banks2.htm

Banks, J.A. (1997). Educating citizens in a multicultural society. New York: Teacher College Press.

Castro, L.N. \& Galace, J.N. (2010). Peace education: a pathway to a culture of peace. Philippines: Centre for Peace Education

Creswell, J.W. (1994). Research design: Qualitative and quantitative approaches. California: SAGE Publications.

Djajadi, I. (2004). Kekerasan etnik dan perdamaian etnik: Dinamika relasi sosial di antara Dayak, Melayu, Cina \& Madura di Kalimantan Barat. Diambil pada tanggal 3 Oktober 2005, dari http:// www.communalconflict.com/iqbal.do $\underline{\mathrm{c}}$
Fullan, M. (Ed.) (1997). The challenge of school change: A collection of articles. Illinois: SkyLight Training and Publishing, Inc.

Guba, E. G., \& Lincoln, Y.S. (1981). Effective evaluation: Improving the usefulness of evaluation results through responsive and naturalistic approach. San Fransisco: Jossey-Bass Publishers.

Gollnick, D.M., \& Chinn, P.C. (2006). Multicultural education in a pluralistic Society. $7^{\text {th }}$ edition. New Jersey: Pearson Education, Inc.

Hammond, L.D. (Ed.) (1993). Review of research in education. New York: American Educational Research Association.

Jamal, M., \& Pähler, Klaus. (Eds.) (2002). Communal conflicts in contemporary Indonesia. Jakarta: Pusat Bahasa dan Budaya IAIN Jakarta \& The Konrad Adenauer Foundation.

Kaufman, R., \& Thomas, S. (1980). Evaluation without fear. New York: New Viewpoints.

Kivimäki, T. (Ed.) (2002). Democracy, decentraliation, identity and conflict in Indonesia. Helsinki \& Copenhagen: CTSConflict Transformation Service.

Nursalim, M., et al. (Eds.) (2002). Damai selalu untuk Indonesia: Dialog budaya antarsuku di Kalimantan Timur. Yogyakarta: Komunitas Ombak.

Malti (2011). Holistic understanding of peace education. Scholar's Voice, 2 (1), 174-177.

McMillan, J.H., \& Schumacher, S. (2001). Research in education: A conceptual introduction. $5^{\text {th }}$ edition. New York: Addison Wesley Longman, Inc.

Semiawan, C. (2003). Memelibara integrasi sosial dan menegakean HAM melalui pendidikan multikultural. Diakses tanggal 25 Januari 2009, dari http://www. wahanakebangsaan.org/index.php?op

Model Pendidikan Multikultural RAMAH Sekolah - 213

Iwan Supardi, Sumarno 
tion $=$ com content\&task $=$ view \&id $=4$ 2\&Itemid $=33$

Stark, J.S., \& Thomas, A. (1994). Assessment and program evaluation. Massachusett: Simon \& Schuster Custom Publishing.

Swetnam, L. A. (2003). Lessons on multicultural education from Australia and the United States [1]. The Caring House. Artikel 581243701. Diambil pada tanggal 11 September 2005, dari http://proquest.umi.com/pqdweb

Trijono, L., et al. (Eds) (2004). Potret retak nusantara: Studi kasus konflik di Indonesia. Yogyakarta: CSPS Books.

Walker, A., \& Dimmock, C. (2005). Leading the multiethnic school: Research evidence on successful practice. The Edu- cational Forum. Artikel 858856741. Diakses tanggal 10 September 2005 dari http://proquest.umi.com/pqdweb

Wessells, M. (1994). Peace education: a psychological perspective. Diakses pada tanggal 12 Desember 2013, dari http:// www.psysr.org/about/committees/p eace education/overview.php

Worthen, B.R., \& Sander, J.R. (1981). Educational evaluations: Theory and practice. Ohio: Charles A. Jones Publishing Company.

Yaqin, M.A. (2005). Pendidikan multikultural: 'Cross-cultural understanding' untuk demokrasi dan keadilan. Yogyakarta: Pilar Media. 